\title{
The Effect of Concentration And Temperature on The Activities of Polar and Semi Polar Mango Peel Extract as Iron Corrosion Inhibitors In Solution of $\mathrm{NaCl} 1 \%$
}

\author{
Tety Sudiarti ${ }^{1}$, Asep Supriadin ${ }^{2}$, Desanti Sarifufah ${ }^{3}$, Citra Fitriani Kusman ${ }^{4}$ \\ \{tety.sudiarti@uinsgd.ac.id ${ }^{1}$, asupriadin@uinsgd.ac.id ${ }^{2}$, sarifufahdesanti@gmail.com³ $^{3}$, \\ citrafitriani@uinsgd.ac.id ${ }^{4}$ \} \\ Chemistry Department, Universitas Islam Negeri Sunan Gunung Djati Bandung, Bandung, \\ Indonesia ${ }^{1,2,3,4}$
}

\begin{abstract}
In the mining industry (petroleum) organic acids that have low molecular weight such as formic acid and acetic acid when mixed with water will become a corrosive medium on the inside of the iron used in production. The use of inhibitors is the cheapest, easiest, most effective, and environmentally friendly corrosion control technique so that it is widely applied in various industrial fields, such as the petroleum mining industry. The purpose of this study was to determine the corrosion inhibition efficiency and activation parameters of the polar and semi-polar mango peel extract compound as an iron corrosion inhibitor in electrolyte solutions. Mango peel extract was obtained through the extraction process using maceration methods identified by the phytochemical test and FTIR on extracts obtained. Mango peel extract contains flavonoids, alkaloids, and tannins. This compound has the opportunity to be used as a corrosion inhibitor because it has high electron density and contains nitrogen atoms with free electron pairs so that it allows strong adsorption on metal surfaces and increases corrosion inhibition activity. The inhibition activity was analyzed by the wheel test method or measurement of weight loss with variations in concentration and temperature. The media used in $\mathrm{NaCl} 1 \%$ electrolyte solution. The inhibition activity of mango peel extract increased with increasing inhibition concentration. In the compound of polar mango peel extract obtained optimum inhibition efficiency at a concentration of $48 \mathrm{ppm}$ was $62.7572 \%$. Whereas in the semi polar mango peel extract compound the optimum inhibition efficiency was obtained at a concentration of $40 \mathrm{ppm}$ with inhibition efficiency of $90.0807 \%$. Based on the results of SEM, Iron without inhibitors and not by immersion in an electrolyte solution such as slabs, iron with immersion in an electrolyte solutions only such as corroded and iron with the addition of inhibitors and immersion in an electrolyte solutions seen to protect the iron from corrosive.
\end{abstract}

Keywords: Corrosion Inhibitor, Mango Peel Extract, Wheel Test Method, SEM.

\section{Introduction}

Since 2000, the world has opposed the shortage of iron ore and steel raw materials in the international market due to the increasing demand for steel in developed or developing countries. Iron ore is used for steel industry purposes. Together with coal, iron is the main mineral needed by humanity to maintain civilization. Both of these mining materials are very widely used, in addition to petroleum, and building materials for physical development purposes. Based on the results of an inventory by the Ministry of Economy of West Germany (1980), iron is the fifth most used mineral by humans, reaching 888 million tons[1]. More 
contain is relatively stronger, harder, shiny, and resistant to heat and cold, but mineral acids with high reactivity can cause corrosion of the iron. Because it is needed in part to avoid losses caused by corrosion.

Redox reactions use a role in everyday life. Redox reactions involve the reaction of half cells with loss of electrons. Half cell reactions involve capture electrons. The reducing agent acts as an electron donor to oxygen until oxygen is reduced. The oxygen is reduced as an oxidizing agent[2]. Corrosion is a redox reaction between a metal and various substances in its environment that cannot be desired which can reduce the quality of a material. One of the corrosion events that is often found in the industrial sector is in the mining industry (petroleum). In this industry the crude oil produced is still mixed with chloride salts, gases containing acids such as $\mathrm{CO}_{2}$ and $\mathrm{H}_{2} \mathrm{~S}$, and other organic acids that contain many low molecules, which when mixed with air will be a highly corrosive medium for the results in carbon steel pipes used in production wells. This corrosive environment is more focused on $\mathrm{NaCl}$ reserves with high and saturated contributions.

As a cheap, effective and efficient way to prevent corrosion by changing the environmental factor with using corrosion inhibitors that based on the source are distinguished from organic and inorganic inhibitors. The selection of an inhibitor is not only based on its ability in coordination with high efficiency, but also needs to be considered[3]. Consideration of expensive prices and higher levels of toxicity has developed alternative sources of cheap and environmentally friendly organic inhibitors from extracts of natural ingredients.

Mango peel has a chemical content that is designated as a corrosion inhibitor. Research conducted by the Department of Biochemistry at the University of Sri Venkatawara Tirupati in India in 2016 gave information about the mango peel positive contain flavanoid, penol and high antioxidants. Organic compounds contained in the peel of mangoes can be used as corrosion inhibitors. Temperature and concentration of an inhibitor can affect the effectiveness of work in inhibiting corrosion[4].

The purpose of this study is to utilize waste from mango peel so that it can be used as a corrosion inhibitor that does not require expensive costs. In the extraction process methanol was used as a polar and ethyl acetate as a semi-pola. Methanol is an organic solvent that will dissolve polar active substances and ethyl acetate is a semi polar organic solvent which will dissolve semi polar active substances.

\section{Experimental}

\subsection{Materials}

The materials to be used in this research are mango peel, methanol, ethyl acetate, ferrous metal, sodium chloride $(\mathrm{NaCl})$ pa, ferri chloride $\left(\mathrm{FeCl}_{3}\right)$, magnesium $(\mathrm{Mg})$, Chloride acid $(\mathrm{HCl})$, Dragenrof reagent, distilled water, silicon carbide, and inhibitor.

\subsection{Instrumentation}

The instrumentation used include analytic balance, sliding length, thread, beaker, measuring flask, measuring cup, spatula, stirring rod, and the instrument used is FTIR (Fourier Transform Infra Red). 


\title{
2.3 Preparation of Mango Peel
}

The peel of mango which has been quenched and separated, cut into small pieces and dried at room temperature, then mashed with a blender until a fine powder is formed.

\subsection{Extraction of Mango Peel}

Weighed $500 \mathrm{~g}$ of powdered mango peel put into a glass bottle, then added solvents each methanol and ethyl acetate. Maceration is done 3 times 24 hours. Where every 24 hours ethyl acetate and methanol extracts are filtered and macerated again with new ethyl acetate and methanol. The ethyl acetate extract and methanol of mango peel obtained were evaporated using a vacuum rotary evaporator at a temperature of $30-40^{\circ} \mathrm{C}$ until thick ethyl acetate and methanol extracts were formed.

\subsection{Characterization of mango peel extract}

\section{Phytochemical Test}

\section{Tanin Test}

The test extract solution is given $2-3$ drops of $1 \% \mathrm{FeCl} 3$ solution, a positive result is indicated by the formation of a green or bluish color.

\section{Flavanoid Test}

The test extract is added with a little $\mathrm{Mg}$ powder, atOH solution: $\mathrm{HCl}(1: 1)$ and amyl alcohol, a positive sample is indicated by the formation of red, yellow or green.

\author{
Alkaloid Test \\ The sample is added 1-2 drops of Dragendroff, the alkaloid is positive if the solution is \\ orange
}

\section{FTIR Analysis}

Polar and semi polar mango peel extracts were tested using FTIR instruments.

\subsection{Preparation of Inhibitor Solutions}

$0.1 \mathrm{~g}$ of mango peel extract powder is weighed in a watch glass, dissolved with distilled water up to $100 \mathrm{~mL}$ to get a solution with a concentration of $1000 \mathrm{ppm}$, then stir until homogeneous.

\subsection{Preparation of $1 \% \mathrm{NaCl}$ solution}

This $1 \% \mathrm{NaCl}$ electrolyte solution is made by weighing $10 \mathrm{~g}$ of solid $\mathrm{NaCl}$ which is then dissolved in a beaker and diluted into a $1 \mathrm{~L}$ measuring flask with distilled water and homogenized. 


\subsection{Preparation of Iron Sample (Wheel Test)}

The iron surface is smoothed with silicon carbide sandpaper, iron specimens are cut, then lathed in diameter according to the tool set. Digitized then weighed.

\subsection{Inhibition Test with the Wheel Test Method}

Test solutions with variation concentrations of inhibitor $(8 \mathrm{ppm}, 16 \mathrm{ppm}, 24 \mathrm{ppm}, 32 \mathrm{ppm}$, $40 \mathrm{ppm}, 48 \mathrm{ppm}, 56 \mathrm{ppm}$, and $64 \mathrm{ppm}$ ) that have been made are inserted into vial bottles. Then the iron metal is immersed in the test solution, closed, and allowed to stand for 45 hours. Then the metal is removed, cleaned, dried, and weighed. The treatment was repeated with the effect of temperature variations are $25,35,45$ and $55^{\circ} \mathrm{C}$.

\subsection{Surface analysis by Scanning Electron Microscope (SEM)}

Test solutions with concentrations of $40 \mathrm{ppm}$ and $48 \mathrm{ppm}$ were made in vial bottles. Then the iron metal is immersed in the test solution, closed and allowed to stand for 45 hours at $25^{\circ} \mathrm{C}$. Then the iron metal is removed cleaned, dried, then carried out with scanning electron microscopy (SEM) analysis.

\section{Result and Discuss}

An inhibitor is a method of protection that is flexible and able to provide protection to the environment. In this case the inhibitor which acts as a protection for iron metal originates from mango peel waste which is carried out several stages of preparation and also testing so that the extract of mango peel is able to act as an iron corrosion inhibitor.

The method used is the wheel test method by using iron specimens in electrolyte solutions including various inhibitor concentrations on corrosion rates and the effectiveness of inhibitors at various temperatures against the effectiveness of inhibitors.

\subsection{Characterization of mango peel extract}

Mango peel extract have high antioxidants, flavanoid, tannin and alkaloid contents that qualify as inhibitors. One of the requirements of a compound that can be used as a corrosion inhibitor is to have inhibitor characteristics of organic compounds such as the presence of heteroatoms, polar groups, bonds and free electron pairs which are the means for inhibitors to bind to metal in coordination. Therefore, to prove that mango peel extract can be used as a corrosion inhibitor, several stages of testing are carried out.

\subsubsection{Phytochemical screening}

Phytochemical screening was carried out after the extract of mango peel was obtained by maceration. Phytochemical screening of polar (methanol) and semi polar (ethyl acetate) mango peel extract showed positive results containing tannins, alkaloids and flavonoids. Alkaloids have nitrogen bases in their cyclic chains and contain various subtituents so that alkaloids are semi polar. Tanin is a polyphenol group which is divided into two groups, namely hydrolyzed tannins and condensed tannins resulting from blackish green tannins showing that the tannins in mango peel extract are non-polar condensed tannins. Flavanoids have an unsubstituted hydroxy group so they are polar. Phytochemical test results show that semi polar solvents have higher concentrations of results compared to the results of polar solvents.

Table 1. Phytochemical Test Results of Polar and Semi Polar Mango Peel Extract

\begin{tabular}{ccc}
\hline Secondary Metabolites & Semi Polar & Polar \\
\hline Alkaloid & + & + \\
Flavanoid & ++ & + \\
Tanin & ++ & + \\
\hline
\end{tabular}




\subsubsection{Fourier Transform Infra Red (FTIR)Analysis}

FTIR method is a test method for determine functional groups of a material based on infrared light intensity absorbed by samples of polar and semi polar mango peel extract. From the results, the graph of analysis is obtained as shown in Figure 1 and Figure 2 as follows:

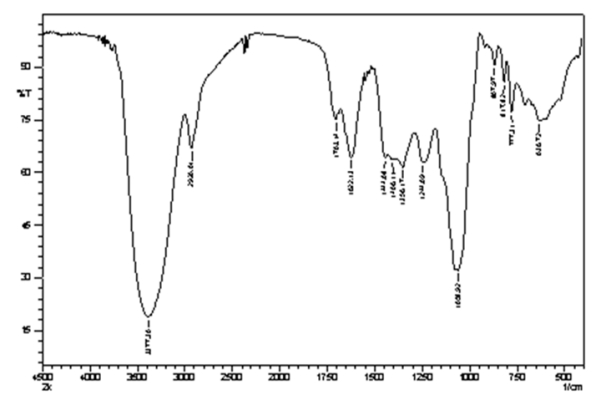

Figure 1. FTIR Result of Polar Mango Peel Extract with Polar (Methanol)

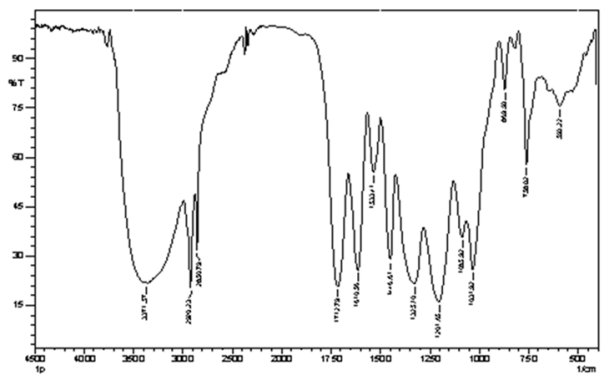

Figure 2. FTIR Result of Semi polar Mango Peel Extract

Table 2 Phytochemical Test Result of Polar Mango Peel Extract with Polar (Methanol)

\begin{tabular}{|c|c|c|c|c|}
\hline Types & Compound Type & $\begin{array}{c}\text { Literature } \\
\text { Frequency } \mathrm{cm}^{-1}\end{array}$ & Polar (Methanol) & $\begin{array}{c}\text { Semi polar } \\
\text { (ethyl acetate) }\end{array}$ \\
\hline$\overline{\mathrm{O}-\mathrm{H}}$ & Alcohol, phenol, $\mathrm{H}$ bond & $2000-3600$ & $3377 ; 2926$ & $2920 ; 2850 ; 3371$ \\
\hline $\mathrm{C}=\mathrm{O}$ & $\begin{array}{l}\text { Aldehide, keton, carboxylic } \\
\text { acid, esters }\end{array}$ & $1690-1760$ & & 1712 \\
\hline $\mathrm{C}=\mathrm{C}$ & Alkenes & $1610-1680$ & 1622 & 1610 \\
\hline O-H & Phenol, alcohol monomer & $3200-3600$ & & 3371 \\
\hline $\mathrm{C}-\mathrm{O}$ & $\begin{array}{l}\text { Alcohol, ether carboxylic acid, } \\
\text { esters }\end{array}$ & $1050-1300$ & 1058 & 1201 \\
\hline $\mathrm{C}-\mathrm{H}$ & Alkane & $1340-1470$ & $1350 ; 1406 ; 1444$ & \\
\hline
\end{tabular}

Based on FTIR results shown in Figure 1 for mango peel extract with ethylacetate fraction and Figure 2 for mango peel extract with methanol fraction consisted of $\mathrm{OH}^{-}, \mathrm{C}=\mathrm{O}$ (carboxylic acid), $\mathrm{C}=\mathrm{C}$ (alkene), $\mathrm{C}-\mathrm{H}$ (alkane), $\mathrm{C}=\mathrm{C}$ (alkene) group. The $\mathrm{O}-\mathrm{H}$ group (hydroxil) is shown at 
$3371 \mathrm{~cm}^{-1}$ frequency. The $\mathrm{C}-\mathrm{H}$ aromatic group (penyl) is indicated by the frequency of 1350 $\mathrm{cm}^{-1}, 1406 \mathrm{~cm}^{-1}, 1444 \mathrm{~cm}^{-1}$ which shows polyphenol compounds are polar, $\mathrm{C}=\mathrm{O}$ (carbonyl) is indicated by the frequency of $1712 \mathrm{~cm}^{-1}$ which is heteroatom which indicates that there is adsorbed ability on the iron surface. The active group in mango peel extract is an aromatic phenolic compound which acts as an anti-oxidant and heteroatom which is adsorbed on the iron surface. The functional groups obtained from FTIR results are functional groups found in flavanoid compounds with spectra regions which are read about $3000-500 \mathrm{~cm}^{-1}$ and are included in the middle IR. So that the pure isolates obtained from the results of the study can be thought to be flavanoid compounds.

\subsection{Result of the Wheel Test Analysis}

The mango peel extract obtained was then applied as a corrosion inhibitor using the method. Wheel Test which is a method of measurement on weight measurements on metal specimens welded during medium corrosion. This measurement compares the weight of the initial specimen which is then compared with the final heavy specimen then immersion in the corrosion medium.

Before this process is carried out it is necessary to prepare in advance for the metal specimens to be approved. The iron metal must be clean by cleaning it using sandpaper, washing it with a spare asset and drying it with a dry tisue. After this metal can be ascertained to be clean, it is measured the iron length, iron width, iron height, and iron weight.

The results obtained from the analysis using the wheel test method by obtaining up, increasing, and rising inhibitors again are caused by the activity of the availability of electrolytes which have high conductivity which can penetrate metals. The weakening of metal bonds is caused by the reduction of the amine group in the bond. Increasing the amine molecule formed is adsorbed by the metal so that it causes the corrosion rate to rise.

The $\mathrm{NaCl}$ solution will break down into ion ions which form anions and cations. These ions make $\mathrm{NaCl}$ solution capable of delivering an electric charge that is distributed in the solution so that $\mathrm{NaCl}$ is able to produce conductivity values. The corrosion process is an electrochemical reaction between metals as an anode with an environment acting as a cathode. How to connect between electrolyte solutions that connect between the anode and cathode will determine the speed of the electrochemical reaction. The solution with conductivity that will continue the corrosion reaction will increase rapidly. With the presence of ions in saline solution will be able to reduce the preduction agent present in the solution [5].

\subsubsection{Effect of Inhibitor Concentration on Corrosion Rate at a Temperature of $25^{\circ} \mathrm{C}$}

The results of measurement of the amount of resistance to corrosion with the wheel test method at $25^{\circ} \mathrm{C}$, showed the effect of inhibitor concentration inversely proportional to the corrosion rate. Corrosion rate decreases with increasing concentration used in the test solution. This shows that the quality of mango peel extract is used as a corrosion inhibitor. This is shown by the graph obtained in Figure 3 and Figure 4. 


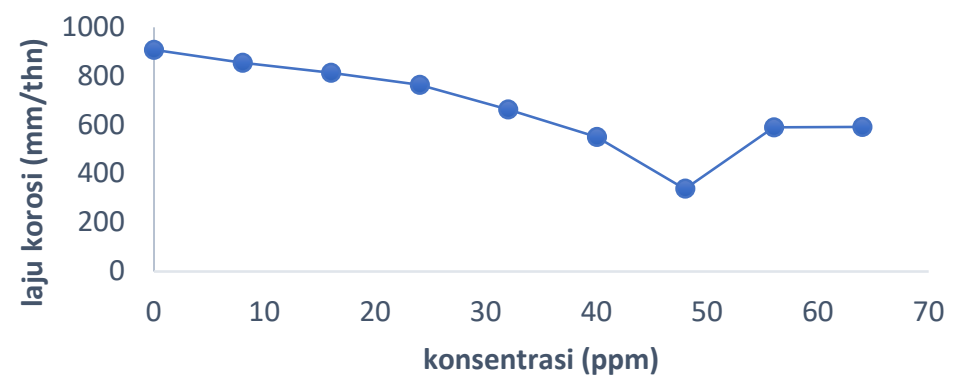

Figure 3. Corrosion Kate with C'oncentration Variation on $25^{\circ} \mathrm{C}$ of Polar Mango Peel Extract

The correlation of the corrosion rate to the polar extract inhibitor concentration is shown in Figure 3. The corrosion rate obtained tends to decrease for each increase in inhibitor concentration. On the addition of inhibitors of the polar mango peel extract, the optimum corrosion rate was obtained at a concentration of $48 \mathrm{ppm}$.

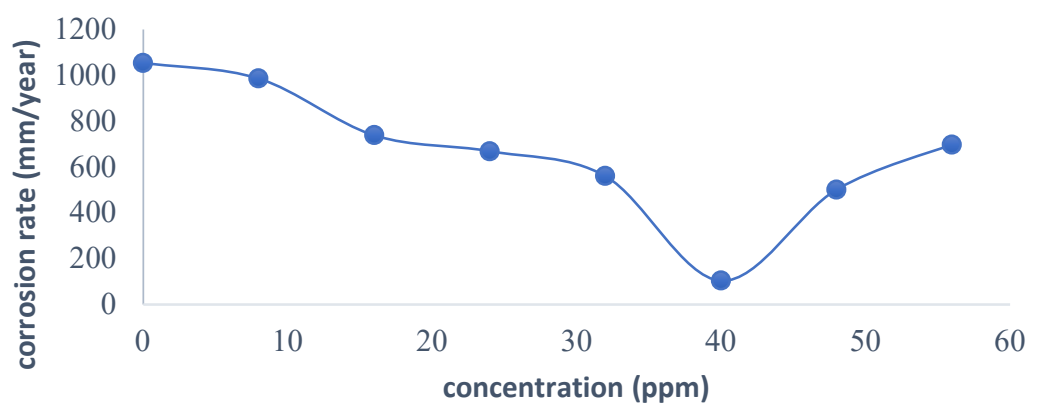

Figure 4. Corrosion Rate with Concentration Variation on $25^{\circ} \mathrm{C}$ of Semi Polar Mango peel Extract

The correlation of the corrosion rate to the inhibitor concentration of semi polar mango peel extract is shown in Figure 4 Where the corrosion rate obtained tends to decrease for each increase in inhibitor concentration. On the addition of inhibitors of semi polar mango peel extract, the optimum corrosion rate was obtained at a concentration of $40 \mathrm{ppm}$.

From the two graph results above the rate of corrosion reaction with the addition of mango peel extract inhibitors both polar and semi polar obtained by each optimum point and when compared with the corrosion rate without the addition of corrosion rate inhibitors with the addition of inhibitors in electrolyte solutions decreased this is due to the presence of hydroxy function group. This hydroxy group can form complex compounds on metal surfaces. So that the corrosion rate will decrease. This complex compound will block the attack of corrosive ions on the metal surface.

The higher the inhibitor concentration the lower the corrosion rate produced, this is due to the ability to oxidize the anodic surface lower than the corrosion medium. So that the ability to inhibit the corrosion will be higher. The inhibitor can influence the corrosive rate of the metal in the corrosive media if the inhibitor can influence electrochemical behavior[6]. This 
phenomenon occurs when thick films and inhibitors are used to form on the metal surface with either an interaction or an adsorption process formed. A thin inner film protective layer on the surface of the metal in a corrosive medium thereby reducing the corrosion rate. Therefore, anodic reactions can be considered as a step in determining the rate in the corrosion process[7]. Factors that affect the corrosion rate include the anode, cathode, electron and conductor transfer media. Of the four media having different functions, namely the anode as the cause of the anodic reaction, the anode acts as an electron donor to the cathode because the properties of the metal are more reactive. Electron transfer occurs because of the potential difference between the anode and cathode. Anodes are usually corroded by releasing electrons from neutral metal atoms to form the corresponding ions. These ions remain in solution or react to form the results of insoluble corrosion. This reaction can block further metal dissolution called passivation where the corrosion reaction stops. The cathode is the site of the reduction reaction where positive ions gather. At the cathode usually does not corrode. Two important reactions that generally occur at the cathode. The presence of electron transfer media can cause corrosion, because of the transfer of electrons in the presence of electrical contact. Electrical contact can occur in electrolyte environments.

\subsubsection{Effect of Inhibitor Concentration on Inhibitor Efficiency at a Temperature of $25^{\circ} \mathrm{C}$}

Concentration and temperature can give effect to inhibitor efficiency[8]. The effect of inhibitor concentrations of the compounds of mango peel extract from the polar mango peel extract and compounds of semi polar mango peel extract on the effectiveness of inhibitors at a temperature of $2525 \mathrm{C}$ were directly proportional. The optimum efficiency value obtained from the results of the mango peel extract compound with a polar mango peel extract was at a concentration of $48 \mathrm{ppm}$ while the compound of the semi polar mango peel extract was at a concentration of $40 \mathrm{ppm}$. These results can be seen from the following graph:

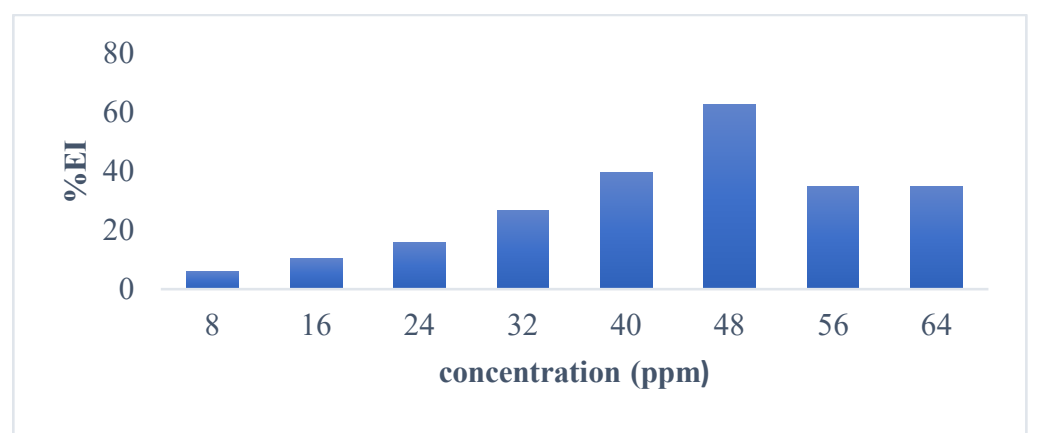

Figure 5. Inhibition Efficiency with variation concentration on $25^{\circ} \mathrm{C}$ of Polar mango peel extract

Figure 5 shows that the highest inhibition efficiency of polar mango peel extract is at a concentration of 48 ppm with an efficiency of $62.7572 \%$. In Figure 6 shows that the highest inhibition efficiency of semi polar mango peel extract is at a concentration of $40 \mathrm{ppm}$ with an efficiency of $90.0807 \%$.

In Figure 5 and Figure 6 the results of the optimum efficiency are different, compared to the two. the inhibitor efficiency of the compound of mango peel extract of the semi polar (Ethyl 
acetate) was higher than that of the polar (methanol) mango peel extract because this was because ethyl acetate was easily evaporated, was not hydrolytic and had low toxicity. Ethyl acetate is a semi polar solvent that is able to attract aglycone and glycone compounds from the peel of mango so that secondary metabolites contained in it are completely dissolved.

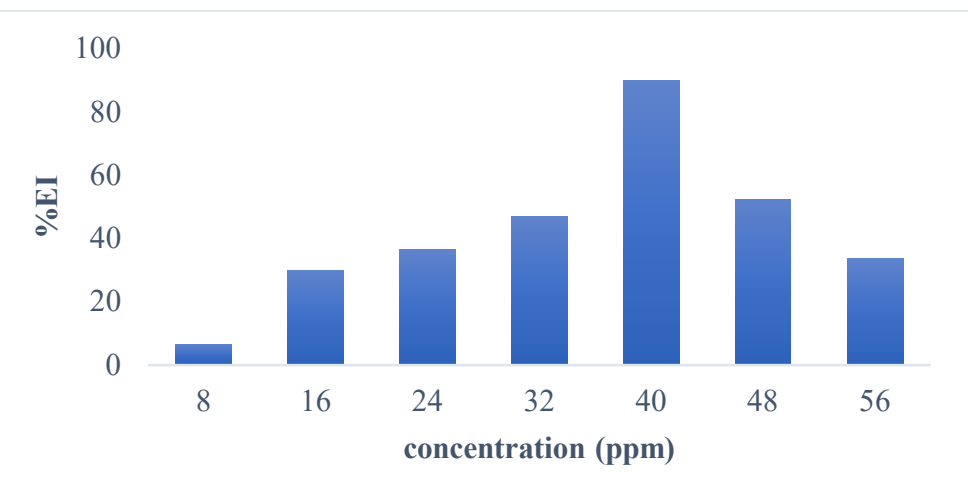

Figure 6. Inhibition Efficiency with variation concentration on $25^{\circ} \mathrm{C}$ of Semi Polar Mango Peel Extract

\subsubsection{Effect of Temperature on Inhibitor Efficiency}

Temperature variations were also carried out to determine the optimum efficiency of inhibitors of mango peel extract which was influenced by temperature at a concentration of $48 \mathrm{ppm}$ for inhibitors with polar (methanol) and at concentrations of 40ppm for inhibitors with semi polar (ethyl acetate). The temperature used in this measurement is $25^{\circ} \mathrm{C}, 35^{\circ} \mathrm{C}, 45^{\circ} \mathrm{C}$ and $55{ }^{\circ} \mathrm{C}$. The results of testing the temperature variations on the inhibitors of mango peel extract are shown in Figure 7:

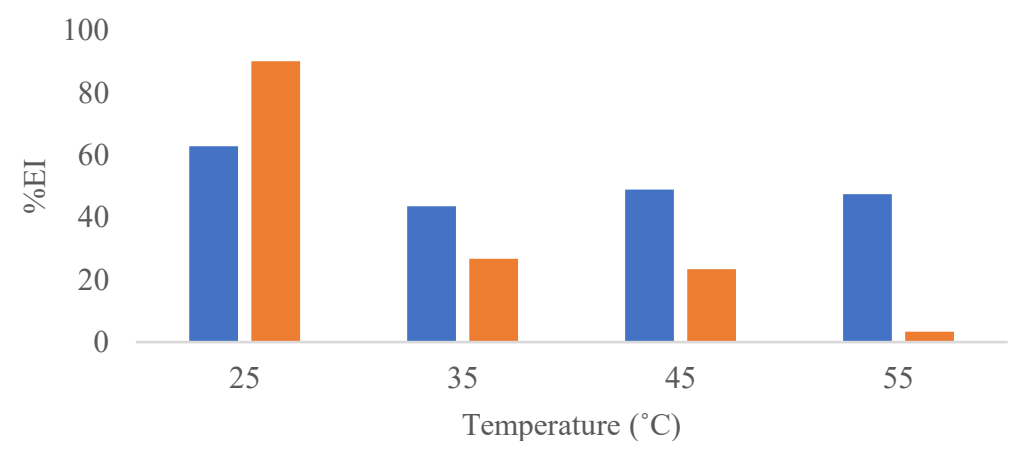

Figure 7. Effect of Temperature on Inhibitor Effectiveness 
Figure 7 there is an increase in the corrosion rate which results in a decrease in the value of its inhibitor effectiveness. High temperatures have a dual effect on the metal degradation they cause. The increase in temperature will affect the thermodynamic aspects and reaction kinetics, meaning that degradation will be faster at higher temperatures, rising temperatures can also affect and change the structure and behavior of metals[9]. If it is structurally changed to eat in general the strength and behavior of the metal also changes.

In addition to degradation in the form of physical damage to the surface or external damage, there is also a degradation in the decrease in mechanical properties resulting in the metal becoming brittle. In the figure, the corrosion rate moves negatively so that the corrosion rate increases. The increase in temperature can reduce the efficiency of inhibition and cause a rusting process which is very fast. Therefore, the optimum temperature in the temperature variation that has been done is at room temperature.

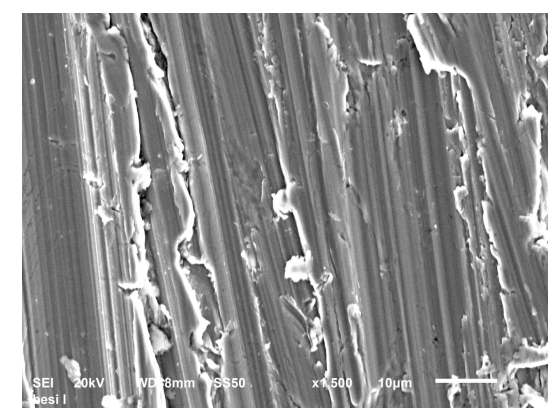

(a)

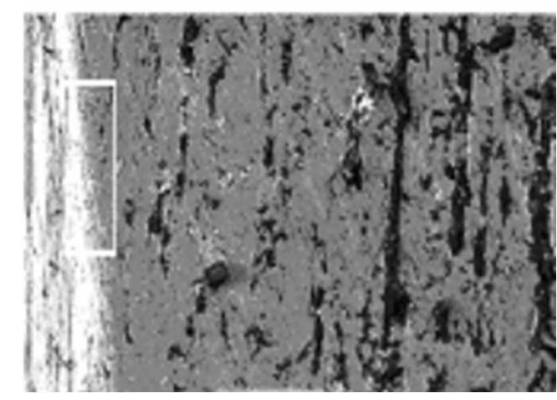

(c)

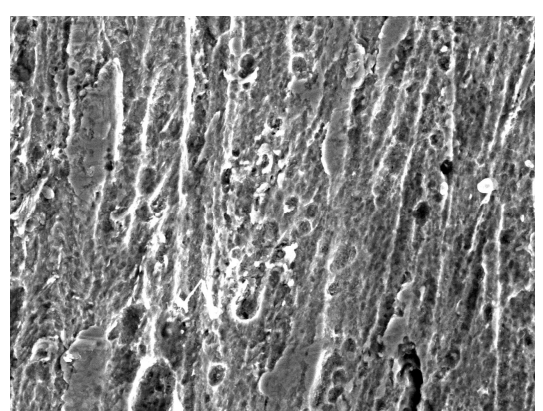

(b)

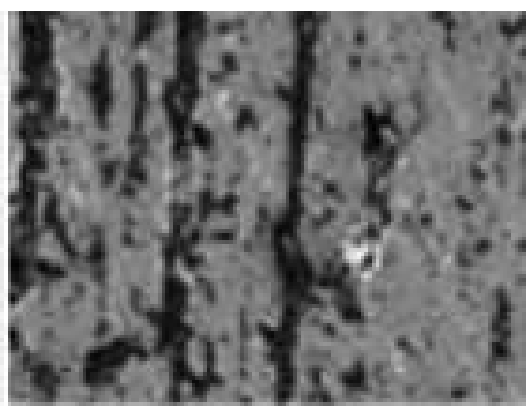

(d)

Figure 8 The surface analysisi by SEM: (a) Iron without inhibitors and not by immersion in an electrolyte solution (b) Iron with immersion in an electrolyte solutions only (c) Iron with the addition of inhibitors polar mango peel extract and immersion in an electrolyte solutions (d) Iron with the addition of inhibitors semi polar mango peel extract and immersion in an electrolyte solutions

\subsubsection{Scanning Electron Microscope (SEM) Analysis}

To ascertain whether corroded iron slabs can be inhibited by inhibitors from mango peel extract, surface analysis was carried out using scanning electron microscope (SEM). In this 
analysis the iron plates used as corrosion media are placed and taped above the cross section which leads vertically to the objective lens. When the electron beam is scanned at the surface of the sample, there is an electron interaction with atoms on the surface and below the surface of the sample. As a result of this infection most of the electron beams get out again, these electrons are called Backscattered electron (BSE). A small portion of the electrons enters the material and then moves a large portion of the energy to the electron atoms so they bounce off the surface of the material, Secondary Electron (SE). The following are the results of SEM measurements for corrosion inhibitors of the compounds of mango peel extract:

Based on the Figure SEM analysis with iron slabs used as corrosion media can be seen that the iron surface appears flat and there is no something that shows iron is corroded or it can be said that the iron is in good condition and clean. The iron plates in electrolyte solutions showed that the iron plates were corroded by the presence of ions in an electrolyte solution which caused the iron surface not to be as intact as before. Based on the results of measurements in Figure 8, it shows that the surface layer of the iron plate is seen to be covered by a corrosive inhibitor caused by an electrolyte solution that is not visible. This shows that the compound of mango peel extract can be used as a corrosion inhibitor because it can protect the iron surface which is exposed to corrosion by electrolyte solutions.

\section{Conclusion}

The results of this research are:

1) Based on the results of FTIR and phytochemical test of the compounds contained in the extracts of mango peel are flavanoids, tannins, and alkaloids.

2) The optimum concentration obtained for corrosion inhibitors from polar and semipolar mango peel extract in a row is $48 \mathrm{ppm}$ and $40 \mathrm{ppm}$.

3) The optimum temperature used for the inhibition corrosion process by the extract of mango peel is $25^{\circ} \mathrm{C}$.

4) The results of SEM analysis, Iron without inhibitors and not by immersion in an electrolyte solution such as slabs, iron with immersion in an electrolyte solutions only such as corroded and iron with the addition of inhibitors and immersion in an electrolyte solutions seen to protect iron from corrosive.

\section{Reference}

[1] T. Ishlah. "Potensi bijih besi Indonesia dalam kerangka pengembangan klaster industri baja", Buetin sumber daya Geologi, Vol 4, No. 2, 2009.

[2] F. Nugroho, "Penggunaan inhibitor untuk meningkatkan ketahanan korosi pada baja karbon rendah," Angkasa, vol. 7, no. 1, pp. 151-158, 2015.

[3] Z. T. Khodair, A. A. Khadom, and H. A. Jasim, "Corrosion protection of mild steel in different aqueous media via epoxy/nanomaterial coating: Preparation, characterization and mathematical views," J. Mater. Res. Technol., vol. 8, no. 1, pp. 424-435, 2019.

[4] K. Krishnaveni and J. Ravichandran, "Effect of aqueous extract of leaves of Morinda tinctoria on corrosion inhibition of aluminium surface in $\mathrm{HCl}$ medium," Oral Oncol., vol. 50, no. 10, pp. 2704-2712, Oct. 2014.

[5] M. Maldonado, M. D. Oleksiak, S. Chinta, and J. D. Rimer, "Controlling Crystal Polymorphism in Organic-Free Synthesis of Na-Zeolites," J. Am. Chem. Soc., vol. 135, no. 7, pp. 2641-2652, Feb. 2013.

[6] M. Allaoui, O. Rahim, and L. Sekhri, "Electrochemical study on corrosion inhibition of 
iron in acidic medium by Moringaoleifera extract," Orient. J. Chem., vol. 33, no. 2, pp. 637-646, 2017.

[7] C. E. Housecroft and A. G. Sharpe, Catherine e. housecroft and alan g. sharpe. 2005.

[8] T. Ibrahim and M. Habbab, "Corrosion inhibition of mild steel in $2 \mathrm{M} \mathrm{HCl}$ using aqueous extract of eggplant peel," Int. J. Electrochem. Sci., vol. 6, no. 11, pp. 5357-5371, 2011.

[9] K. Ramya and N. Muralimohan, "Study on corrosion inhibitor in mild steel by various habitual plant extract - Review," Int. J. Chem. Concepts, vol. 02, no. 02, pp. 70-75, 2016. 